\title{
The natural history of COPD: confirming and going beyond Fletcher and Peto
}

\author{
Albert Miller ${ }^{1,2}$ and Jonathan M. Raskin ${ }^{1,3}$ \\ Affiliations: 'Dept of Medicine, Albert Einstein College of Medicine, Bronx, NY, USA. ${ }^{2}$ Pulmonary Function \\ Laboratory, Mount Sinai Beth Israel Medical Center, New York, NY, USA. ${ }^{3}$ Alice Lawrence Center for Health and \\ Rehabilitation, Mount Sinai Beth Israel Medical Center, New York, NY, USA.
}

Correspondence: Albert Miller, Mount Sinai Beth Israel Medical Center, Pulmonary Division, Dazian 7, First Avenue at 16 th Street, New York, NY, 10003, USA. E-mail: almillermdagmail.com

$\boldsymbol{0}$

@ERSpublications

Findings of Fletcher and Peto confirmed, and importance of early COPD stages in FEV1 decline and treatment emphasised http://ow.ly/xnKns

\begin{abstract}
"The natural history of chronic airflow obstruction", initially published in the BMJ in 1977 by FLETCHER and PETO [1], and preceded by a fuller monograph [2], has long been a part of the landscape of pulmonary medicine. Their insights have helped form our collective thinking as we interpret pulmonary function in relation to ageing and lung disease.

In this issue of the European Respiratory Journal (ERJ), SANCHEZ-SALCEDO et al. [3] contribute to our knowledge of chronic obstructive pulmonary disease (COPD) clinical status and progression in a study of 103 younger and 463 older patients followed for $\geqslant 2$ years. All patients attended specialised pulmonary clinics, had smoked for $\geqslant 20$ pack-years and were (presumably) symptomatic from their physiciandiagnosed COPD. The majority (59\%) of the younger patients were "active smokers" compared with only $20 \%$ of the older group. The rapid decliners in this study may be considered similar to the susceptible smokers who demonstrated rapid decline in the study by FleTCHER and PeTo [1]. The Fletcher-Peto cohort was a random sample of 792 employed middle-aged Caucasian males who were followed for 8 years. Presciently, 37 years ago, this cohort demonstrated that not all smokers are susceptible to losing lung function and that in the susceptible smokers, continued smoking accelerates loss. As in the Fletcher-Peto cohort, which followed only males, and in the BODE (body mass index, airflow obstruction, dyspnoea, exercise capacity) cohort study by CASANOVA et al. [4], in which $92 \%$ were male, the study by SANCHEZSALCEDO et al. [3] is heavily weighted to males, with $85 \%$ of the younger and $92 \%$ of the older patients being male. Data on females were provided by the Framingham Offspring Cohort [5] (4391 community residents followed for 23 years, of whom 51\% were females) and by the Lung Health Study [6] (5885 COPD patients followed for $\geqslant 14.5$ years, of whom $37 \%$ were females). The absence of data on females renders the study by SANCHEZ-SALCEDO et al. [3] less applicable to population analysis for rates of change in forced expiratory volume in $1 \mathrm{~s}(\mathrm{FEV} 1)$. The Framingham cohort showed a lower decline in females who continued to smoke compared with males (23.9 versus $38.2 \mathrm{~mL} \cdot \mathrm{yr}^{-1}$ ), and fewer female smokers who developed airflow obstruction $(24.2 \%)$ than male smokers $(33.0 \%)$ [5].
\end{abstract}

Many of the core findings of FLETCHER and PETO [1] have been confirmed in studies of smokers and/or COPD patients published since their report. A range of susceptible smokers develop airflow obstruction. This range is fairly consistent considering the differences in subject selection: $42-46 \%$ of the clinical COPD patients in the study by SANCHEZ-SALCEDO et al. [3], excluding any with bronchial responsiveness; $33 \%$ of males (24\% of females) in the Framingham cohort [5]; $25 \%$ of the Nishimura group, most of whom had mild-to-moderate COPD [7]; and 18\% in the BODE cohort [4] of "well-characterised" COPD patients (mean forced expiratory volume in $1 \mathrm{~s}$ (FEV1) 46\% predicted). In the study by Fletcher and Peto [2],

Received: April 282014 | Accepted: May 252014

Conflict of interest: None declared.

Copyright @ERS 2014 
387 moderate $\left(\leqslant 15\right.$ cigarettes $\cdot \mathrm{day}^{-1}$ ) continuing smokers lost FEV1 at a rate of $63 \mathrm{~mL} \cdot \mathrm{yr}^{-1}$ and $12 \%$ developed airflow obstruction. This compared with a loss of $78 \mathrm{~mL} \cdot \mathrm{yr}^{-1}$ and development of COPD in $26 \%$ of the 180 heavy smokers in their study. It was suggested that stopping smoking reduced the excessive decline. The study by KoHAnsal et al. [5] demonstrated an important difference to that of FleTCHER and PETO [1]: they showed that discontinuing smoking later in life is less likely to reduce the excessive decline. The decrease in FEV1 of smokers who discontinued their habit later in life was similar to that of continuing smokers. Nevertheless, the recommendation in the study by FLETCHER and PETO [1] that measuring FEV1 should "be used as a screening test to detect susceptible smokers" remains valid, even more so for younger smokers. All clinicians who interact with patients recognise that many smokers remain unaware of their COPD, which is easily detectable by such a simple yet powerful test.

Other considerations have provided insights into changing lung function over time. We are beginning to understand that the heterogeneity of COPD begets different natural histories. Of the many classifications of COPD phenotypes, three have been associated with natural history and response to therapy [8]. These are: the frequent exacerbator; the overlapping COPD/asthma patient; and the emphysema-hyperinflation patient. Although the level of FEV1 is inversely related to the number of exacerbations, the relationship is far from linear. The ECLIPSE (Evaluation of COPD Longitudinally to Identify Predictive Surrogate Endpoints) cohort showed that $53 \%$ of patients with a severely decreased FEV1 did not suffer from exacerbations, while $22 \%$ of those with lesser decreases did suffer from exacerbations [9]. The importance of symptom severity and frequency of exacerbations has been recognised in the revised Global Initiative for Chronic Obstructive Lung Disease (GOLD) Classification [10].

SANCHEZ-SALCEDO et al. [3] have virtually excluded the overlap phenotype by leaving out patients simply because of wheeze (without specifying whether this was a symptom or a finding on auscultation) or bronchodilator response. Many smokers with dyspnoea and cough also wheeze and/or have positive bronchodilator responses, and were included as having a COPD diagnosis. In their study of 300 patients with respiratory physician-diagnosed COPD, Nishimura et al. [7] excluded only those with "clinically diagnosed asthma" and specifically included those with a positive bronchodilator response. This renders the cohort of Nishimura et al. [7] less "real world" as a COPD population and marginalises the effect of medication on lung function. NisHimura et al. [7] noted an overall decline in FEV1 of $32 \mathrm{~mL} \cdot \mathrm{yr}^{-1}$ and reported that $25 \%$ were rapid decliners $\left(63 \mathrm{~mL} \cdot \mathrm{yr}^{-1}\right), 50 \%$ were slow decliners $\left(31 \mathrm{~mL} \cdot \mathrm{yr}^{-1}\right)$ and $25 \%$ were non-decliners $\left(2 \mathrm{~mL} \cdot \mathrm{yr}^{-1}\right)$. There were no differences in spirometry, bronchodilator response, quality of life, smoking, exacerbation rate or medication in the cohort of Nishimura et al. [7]. Distinguishing emphysema (as shown by computed tomography (CT) scan or diffusing capacity) from chronic bronchitis is relevant to lung function decline; no information on CT emphysema or diffusing capacity was provided by SANCHEZSALCEDO et al. [3]. Emphysema (demonstrated by computer score, a visual impression on a CT scan or by diffusion capacity or coefficient) identified the rapid decliners.

Many other variables affect the decline of FEV1 in smokers and COPD patients. SANCHEZ-SALCEDO et al. [3] acknowledge that statin use was more prevalent in the older cohort. Although the data on the impact of statins on lung function decline are at an early stage, statins have been shown to reduce age-related decline in FEV1 [11]. This may have affected the comparison between older and younger patients. Similarly, regular physical activity lessens the decline in FEV1 in active smokers by as much as $25 \%$ and reduces the risk of developing COPD [12]. We do not fault the study on the absence of activity monitoring as this too is at its inception but it is likely that younger and older patients demonstrate different levels of activity, which may be relevant to the ageing lung and FEV1 decline. Recent data on pulmonary rehabilitation in COPD contribute to knowledge about the impact of exercise on lung function decline [13]. The study by SANCHEZSALCEDO et al. [3] does not provide information on other concerns that affect lung function: smoking commencement, burden and duration; second-hand smoke; occupational and environmental exposures; frequency of COPD exacerbations [10]; $\alpha_{1}$-antitrypsin level; and concomitant conditions known to accelerate COPD (e.g. immune status, including HIV infection). Consumption of processed meats is also associated with a lower FEV1 and an increased risk of COPD, as recently discussed in the ERJ [14]. We are now aware that these issues, as well as susceptibility to cigarette smoke and early treatment (discussed further later), begin to explain why histograms of FEV1 loss in smokers and/or COPD patients do not show a steady and inexorable decline $[4,7,15]$.

SANCHEZ-SALCEDO et al. [3] used a FEV1/forced vital capacity lower limit of normal of 0.70, which meant that many of the older patients had normal values for this index of airway obstruction. This fixed cut-off point "leads to substantial overdiagnosis of obstruction" [16].

Major findings of the study by SANCHEZ-SALCEDO et al. [3] are as follows. 
1) Severity distribution according to FEV1, GOLD score and BODE index (which includes the clinically relevant findings of dyspnoea and performance) were similar in the two age groups.

2) Declines in FEV1 and BODE index were similar in the two age groups overall and when stratified by GOLD grade.

3) Percentage of rapid decliners (42\% versus $46 \%)$ and their rates of decline (114 versus $117 \mathrm{~mL} \cdot \mathrm{yr}^{-1}$ ) were similar in the two age groups. These findings may be explained, at least in part, by continued smoking in the younger group (59\% versus $20 \%$ ).

4) Rapid decliners start at higher levels of pulmonary function, or as SANCHEZ-SALCEDO et al. [3] put it, "had milder disease." This is similar to the findings in the BODE cohort [4] and the data in the TORCH study [17], but differs to the findings of DRUMmond et al. [6] as well as the curves in the study by FLETCHER and Pето [1] (as the authors rightfully point out).

5) The considerable (25\%) difference in mortality in the two age groups can be understood from consideration of comorbidities alone, as well as age. A follow-up study of the cohort that considers respiratory mortality would be of interest.

The nonrapid decliners in all studies of smokers and COPD patients remain of great interest: in the study by SANCHEZ-SALCEDO et al. [3], >50\% of COPD patients attending specialised clinics did not progress! This is discernible during clinic follow-up. How many years does one need to follow patients before assigning a designation of "rapid decliner"? And is treatment warranted for the non-decliner? Or is treatment the reason for non-progression? Do nonrapid decliners differ in quality of life or exacerbation rate? Certainly, this large proportion of patients has a different course and should be advised of it. The overarching question is: if nonrapid decliner COPD patients do not lose FEV1 at a rate greater than expected for age, how do they reach the low level noted at diagnosis? The approach taken in the study by SANCHEZ-SALCEDO et al. [3], to look at COPD states and the progression in the two age groups, did not shed light on early COPD before it becomes clinically evident. Restating this, these patients, in both age categories, are already physiciandiagnosed as having COPD, and demonstrate fixed airways obstruction. They were therefore susceptible at an earlier time in their natural history yet more than half do not show excessive loss of lung function at a later stage.

There is a growing body of evidence that treatment may be more beneficial at an earlier stage. Further analyses of patients at an earlier disease stage (GOLD II) or at a younger age $(<50$ years) have shown a reduced decline in post-bronchodilator FEV1 in those treated with inhaled long-acting adrenergic bronchodilators combined with corticosteroid [17] or muscarinic drugs [18, 19]. In addition to medication, pulmonary rehabilitation has been shown to decrease the annual decline in FEV1 in COPD patients with a mean $\mathrm{FEV} 1$ of $48 \%$ pred, although no information was provided on any difference between less and more severe disease [13].

We remain with the observation that a minority of smokers is susceptible to developing fixed airways obstruction and yet not all continue to lose FEV1. We lack an understanding of what determines this susceptibility. It is hoped that advances in the genetics and genetic-environmental interactions of COPD, reviewed in recent papers [20-22], will provide insight into this susceptibility as well as the impact of therapeutic interventions.

In summary, the study by SANCHEZ-SALCEDO et al. [3] has confirmed the near half-century old core findings of Fletcher and Peto, and illuminated the importance of understanding the earlier stages of COPD. Understanding and better defining of the natural history of rapid decline in FEV1, what initiates the process, co-factors mitigating or enhancing this phenomenum and the concern that it starts at a stage of "milder disease" continue to be relevant as we gain insight into ageing and lung function. Together with recent findings on the benefit of activity, earlier use of medication and mitigating exacerbations, we now have a basis for interventions beyond smoking cessation.

\section{References}

Fletcher C, Peto R. The natural history of chronic airflow obstruction. Br Med J 1977; 1: 1645-1648.

Fletcher C, Peto R, et al. The natural history of chronic bronchitis and emphysema. Oxford, Oxford University Press, 1976.

Sanchez-Salcedo P, Divo M, Casanova C, et al. Disease progression in young patients with COPD: rethinking the Fletcher and Peto model. Eur Respir J 2014; 44: 324-331.

4 Casanova C, de Torres J, Aguirre-Jaime A, et al. The progression of COPD is heterogeneous; the experience of the BODE cohort. Am J Respir Crit Care Med 2011; 184: 1015-1021.

5 Kohansal R, Martinez-Camblor P, Agustí A, et al. The natural history of chronic airflow obstruction revisited: an analysis of the Framingham Offspring Cohort. Am J Respir Crit Care Med 2009; 180: 3-10. 
Drummond M, Hansel N, Connett J, et al. Spirometric predictors of lung function decline and mortality in early chronic obstructive pulmonary disease. Am J Respir Crit Care Med 2012; 185: 1301-1306.

7 Nishimura M, Makita H, Nagai K, et al. Annual change in pulmonary function and clinical phenotype in chronic obstructive pulmonary disease. Am J Respir Crit Care Med 2012; 185: 44-52.

8 Miravitlles M, Calle M, Soler-Cataluña J. Clinical phenotypes of COPD: identification, definition and implications for guidelines. Arch Bronconeumol 2012; 48: 86-98.

9 Hurst J, Vestbo J, Anzueto A, et al. Susceptibility to exacerbation in chronic obstructive pulmonary disease. $N$ Engl J Med 2010; 363: 1128-1138.

10 Vestbo J, Hurd S, Agusti A, et al. Global strategy for the diagnosis, management, and prevention of chronic obstructive pulmonary disease: GOLD executive summary. Am J Respir Crit Care Med 2013; 187: $347-365$.

11 Alexeeff S, Litonjua A, Sparrow D, et al. Statin use reduces decline in lung function: VA Normative Aging Study. Am J Respir Crit Care Med 2007; 176: 742-747.

12 Garcia-Aymerich J, Lange P, Benet M, et al. Regular physical activity modifies smoking-related lung function decline and reduces risk of chronic obstructive pulmonary disease. Am J Respir Crit Care Med 2007; 175: 458-463.

13 Stav D, Raz M, Shpirer I. Three years of pulmonary rehabilitation: inhibit the decline in airflow obstruction, improves exercise endurance time, and body-mass index, in chronic obstructive pulmonary disease. BMC Pulmonary Medicine 2009; 9: 26.

14 Varraso R, Camargo CA Jr. Processed meat consumption and lung health: more evidence for harm. Eur Respir J 2014; 43: 943-946.

15 Vestbo J, Edwards LD, Scanlon PD, et al. Changes in forced expiratory volume in 1 second over time in COPD. N Engl J Med 2011; 365: 1184-1192.

16 Schermer T, Smeele I, Thoonen B, et al. Current clinical guideline definitions of airflow obstruction and COPD overdiagnosis in primary care. Eur Respir J 2008; 32: 945-952.

17 Jenkins C, Jones P, Calverley P, et al. Efficacy of salmeterol/fluticasone propionate by GOLD stage of chronic obstructive pulmonary disease: analysis from the randomised, placebo-controlled TORCH study. Respir Res 2009; 10: 59 .

18 Morice A, Celli B, Kesten S, et al. COPD in young patients: a pre-specified analysis of the four-year trial of tiotropium (UPLIFT). Respir Med 2010; 104: 1659-1667.

19 Decramer M, Celli B, Kesten S, et al. Effect of tiotropium on outcomes in patients with moderate COPD (UPLIFT); a prespecified sub group analysis of a randomized controlled trial. Lancet 2009; 374: 1171-1178.

20 Seibold M, Scwartz D. The lung: the natural boundary between nature and nurture. Annu Rev Physiol 2011; 73: 457-478.

21 Castaldi P, Cho M, Litonjua A, et al. The association of genome-wide significant spirometric loci with chronic obstructive pulmonary disease susceptibility. Am J Respir Cell Mol Biol 2011; 45: 1147-1153.

22 Wain L, Soler Artigas M, Tobin M, et al. What can genetics tell us about the cause of fixed airflow obstruction? Clin Exp Allergy 2012; 42: 1176-1182. 